\title{
Petroleum Patent Used Such Monitoring Technological Like Innovation Process of Drilling Fluids with Xanthan Gum -World Panorama
}

\author{
Marco Antonio Martins de Oliveira1, Cheila Gonçalves Mothé1, \\ Leandra Guimarães de Oliveira² \\ ${ }^{1}$ Department of Organic Processes, School of Chemistry, Federal University of Rio de Janeiro (UFRJ), Rio de \\ Janeiro, Brazil \\ ${ }^{2}$ Brazilian National Institute of Industrial Property (INPI), Rio de Janeiro, Brazil \\ Email: $\underline{\text { mmartinsoliver@gmail.com, cheila@eq.ufrj.br, leandra@inpi.gov.br }}$
}

Received 4 June 2015; accepted 11 July 2015; published 14 July 2015

Copyright (C) 2015 by authors and Scientific Research Publishing Inc. This work is licensed under the Creative Commons Attribution International License (CC BY). http://creativecommons.org/licenses/by/4.0/

\section{Abstract}

This paper aims to discuss the importance of patenting and publishing as an instrument of incentive to technological innovation in the petroleum chemistry area. The present study has examined the publications and the patent applications published from 1974 to 2014 . A technological monitoring methodology for patents in drilling fluid with xanthan gum has been compared using profiles of patent application in the world, with emphasis on Industrial Property Databases available on the internet (INPI-Br, Derwent, Espacenet, Patent Scope and USPTO) with intention to assess the main inventors, applications, applications' countries, the IPC classification, years of application and category of claims as well as discuss the importance of patents as a means of encouraging technological innovation of xanthan gum. The United States and China stand out both in relation to the publication of papers as well as in the amount of patent filing in scientific publications with the theme drilling fluid with additive xanthan gum classified by the authors' country of origin. It is observed that Brazil and the US lead the ranking with 15 publications (about $23.1 \%$ of the total). Among the 72 institutions obtained as a result, both Petrobras SA and Universidade Federal do Rio de Janeiro, in Brazil, lead the world ranking, with 6 publications each; in relation to the areas of knowledge, it is observed that engineering stands out in the publication of papers and the areas of chemistry, engineering, energy fuels and polymer science are noticeable in numbers of patent applications. The analysis of patent filings in the periods proposed features a significant percentage associated with the classification C09K. 
Keywords

Drilling Fluid, Xanthan Gum, Technological Monitoring

\section{Introduction}

Drilling wells is an ancient activity whose main objective was to find water. However, the industrialization in late nineteenth century increased the global demand for oil, so the wells were drilled in search of it. Since then many researches about drilling have been made. Many publications reported that the drilling success depends on the composition of the fluid and the care for the maintenance of their properties during drilling [1]. Indeed, drilling fluid represents $15 \%$ to $18 \%$ of the total cost of drilling the oil well and generally must meet three important requirements: 1) easy-handling; 2) low-cost and 3) meeting the requirements of the environment [2]. There are three main types of drilling fluids: the aqueous-based fluid, the oil-based fluid and the synthetic-based fluid. The first, containing polymers, has been extensively used in drilling wells which penetrate formations containing water-sensitive shale, particularly where there are strict environmental laws restricting the use of oiland synthetic-based fluids [3].

In fact, water based fluids (WBF) were the most consumed drilling fluids around the world and accounted for $56 \%$ of the total market revenue in 2013. WBFs are also expected to be the fastest growing drilling fluid products, at an estimated compound annual growth rate (CAGR) of 8.8\% from 2014 to 2020. WBFs were followed by oil-based fluids (OBF) which accounted for just over 30\% of the total market in the same year. However, the growing environmental concerns regarding the use of OBFs in drilling activities are expected to hamper its market growth over the forecast period [4].

The global market for drilling fluids is expected to reach USD 14.92 billion by 2020, by increasing drilling activities mainly in South America and Asia Pacific [4]. Still, this global market is highly concentrated as top four companies including Schlumberger, Halliburton, Baker Hughes and Newpark accounted for over $70 \%$ of the total market in 2013 [4].

One of the additives most used in aqueous-base fluids is xanthan gum. Xanthan gum is an excellent additive for oilfield drilling mud. Its high viscosity in the low shear can help low concentration of the drilling fluid suspend solids [5] and [6]. Even in high temperature, or solutions with high concentration of acid, alkali or salt, xanthan gum still can maintain this property, which is especially important in offshore drilling or other harsh conditions. Xanthan gum is suitable for the tertiary oil recovery and enhanced oil recovery in oil production. Its strong heat resistance properties make it a reliable displacing agent and mobile control agent [7]. However, the rheological behavior of drilling fluids may be altered during perforation due to the temperature gradient of the wellbore. Thermal degradation suffered by certain additives used as viscosifiers restricts the use of the group depending on the change in the temperature to which it will be exposed. Studies show that xanthan gum polymer proved to be suitable for the formulation of fluids which can be used in wellbores with a higher temperature gradient [8].

In this context, many companies realized that technological monitoring is a growing need for organizations competing in dynamic and globalized markets. To accompany major changes in technology in their fields worldwide; to understand the consequences and to take appropriate actions and decisions require strong organization of their monitoring processes. Thus, technological monitoring using patents is an excellent tool that helps in the decision making on investment, giving the value of the information contained in these documents, identifying relevant technologies, market niches, partnerships, innovation and competition movements [9] in ref. [10].

Thus, there was a technological monitoring of products and processes for drilling fluids patents, specifying the use of the xanthan gum in aqueous base, with a comparison of patent applications in Brazil and worldwide, published until 2014 with emphasis on industrial property.

This work is essential to guide and direct the new researches about drilling oil, due to the high investments in the oil sector and its increase with the new discoveries of pre-salt layers reserves, and the competition from big foreign companies with the opening of the domestic market after breaking the monopoly. Giving the importance of consumption and investment by the industry, the study presents technological monitoring of drilling fluids, using patent documents with a search strategy to set free databases in the websites INPI, Espacenet, Derwent, USPTO and Patent Scope. 


\section{Methodology}

The methodology used for monitoring the technological production on the theme of additive for drilling fluid, particularly xanthan gum, was based on direct evaluation of international databases with survey of the scientific literature, using a worldwide database, "Web of Science". To study technology of patents, databases such as INPI, Espacenet, USPTO Patent Scope and Derwent were selected. These surveys covered various search terms and covered the whole period available in the database searches. Then did the technological monitoring, using the database selected in the previous step. In this work, the period from 1974 to 2014 was considered.

\subsection{Non-Patent Database}

\section{Web of Science}

Web of Science is a robust database of the most important data on non-patent literature of the world. Its authorized, multidisciplinary content covers over 12,000 of the worldwide, most leading magazines including freely available journals, over 150,000 conference proceedings, a current and a retrospective coverage in Science, Social Science, Art and Humanities, with contents back from the 1900's. It was essential to deal with the overflow of information and focus on the essential data collected from over 250 subjects. The methodology comprises the following steps:

- Access Journals on CAPES portal:

http://www-periodicos-capes-gov-br.ez29.periodicos.capes.gov.br/index.php?option = com_phome;

- On the main page, in the Search Base field, enter and select the search base Derwent Innovations INDEX/ DII;

- Enter on "Select a Database" folder;

- Enter on the hyperlink "Web of Science";

- Enter the keywords together in the "TOPIC" field with the Boolean operator "OR" ("drilling fluid *xanthan" OR "fluid drilling* xanthan” OR "xanthan* drilling fluid” OR "xanthan* fluid drilling”);

- Enter on the "SEARCH" icon;

- Access on the "Analyze Results" icon.

After the search this database allows the user to analyze the results, by means of charts on the main results relating to authors, countries/territories, document types, editors, language, among others.

\subsection{Patents Database}

\subsubsection{INPI (Instituto Nacional de Propriedade Industrial)}

The search was conducted in the Brazilian patent database from INPI, which is available on the internet free of charges. This database contains data from patents as well as patent applications filed and published in Brazil. The methodology comprises the following steps:

- Access the portal by the PTO homepage: http://www.inpi.gov.br/portal;

- On the main page, enter the folder PATENT;

- Enter on the SEARCH sub-folder within the folder PATENT;

- Enter on "hyperlink" CLICK HERE to carry out a previous search for the INPI Portal;

- Enter the access code;

- Enter on Advanced Search;

- Enter the key words in the title and abstract: (“drilling fluid *xanthan” OR "fluid drilling* xanthan” OR "xanthan* drilling fluid" OR "xanthan* fluid drilling");

- Enter on SEARCH.

\subsubsection{Derwent}

The Word Patent Index is a database produced by Thomson Scientific ${ }^{\circledR}$ and it allows the access to information on more than 40 million patent documents filed in various countries , providing details on over 14.8 million inventions (THOMSON REUTERS, 2008), with the indexing of patent data starting in 1963. This is a database of private access which encompasses worldwide published patent documents, however, given its relevance, it is available on the portal of CAPES, for free consultation by universities, Federal Institutes (IF) Institutes and R \& $\mathrm{D}$ from Brazil. The methodology comprises the following steps: 
- Access Journals CAPES portal:

http://www-periodicos-capes-gov-br.ez29.periodicos.capes.gov.br/index.php?option=com_phome;

- On the main page, in the Search Base field, enter and select the search base Derwent Innovations INDEX/ DII;

- Enter the keywords together in "TOPIC" field with the Boolean operator "OR" (drilling fluid *xanthan" OR "fluid drilling* xanthan" OR "xanthan* drilling fluid" OR "xanthan* fluid drilling”);

- Enter on "SEARCH" icon;

- Access on "Analyze Results" icon.

After the search, this base allows to analyze the outcomes, by means of charts, as well as the main results for depositors, inventors, international classifications and knowledge areas, among others.

\subsubsection{Espacenet}

The patent base Espacenet is kept by the European Patent Office (European Patent Office-EPO) and it enables search on bibliographic data (numbers and dates of publication, filing and priority, IPC classification, inventors, depositors and title) of patents from different countries as well as on the text of the applications. Some of the selected patents can be viewed in their entirety, including drawings, with the possibility of obtaining their corresponding patents. The methodology comprises the following steps:

- Access the basis of the European Patent Office Patents: http://worldwide.espacenet.com/;

- Enter on "ADVANCED SEARCH" folder on the main page;

- Within the item "Select the collection you want to search in", select the "WorldWide" basis which presents a complete collection of indexing patents published in more than 90 countries;

- Type keywords in the "Keyword (s) in title or abstract": drilling fluid *xanthan" OR "fluid drilling* xanthan" OR "xanthan* drilling fluid” OR "xanthan* fluid drilling”);

- Enter on "SEARCH" icon.

\subsubsection{USPTO}

Focusing more specifically on American patents, this database has patent applications from 1976 to the present date. This database of USPTO is weekly updated and it contains more than 7.5 million documents, including utility patents, design patents and plant patents, making this database one of the largest collections of technical information organized in the world. The methodology comprises the following steps:

- Access the Base of the US Patent-USPTO: http://www.uspto.gov;

- On the main page, enter on the "PATENTS" folder and then "Search Patents";

- Enter on "USPTO Patent Full-Text and Image Database (PatFT)" item , select "Advanced Search" icon;

- In the "Query" field, enter the keywords: "drilling fluid and xanthan" or "fluid drilling and xanthan" in the title (TTL) or Summary (ABST). This database allows you to refine your search by means of including supplementary information in other fields, such as "International Patent Classification (IPC)", "Patent number (PN)";

- Enter on "SEARCH" icon.

\subsubsection{Patent Scope}

Patent Scope is a product of the project WIPO IPDL (Digital Library Intellectual Property WIPO). This database contains information on the front pages (bibliographic data, abstract and drawing) of patent applications filed via PCT, published from January 1978. The following methodology was employed search:

- Access the Base Patents WIPO: http://www.wipo.int/portal/index.html.en;

- In the "Gateway" to: folder, enter on the "Patents" field. The page displays the database called "PATENTSCOPE" on page: http://www.wipo.int/patentscope/en/;

- In "Searching and Analyzing" folder, enter on "PATENTSCOPE search";

- Enter on "Search" and then on "Field Combination";

- Enter the keywords drilling fluid *xanthan" OR "fluid drilling* xanthan" OR "xanthan* drilling fluid" OR "xanthan* fluid drilling")* in the fields "English Title" and "English Abstract" combining with the Boolean operators "OR" and the result which was displayed (using the Boolean operator "AND") with the date of the priority (PD);

- Enter on "SEARCH". 


\section{Results and Discussion}

After the screening of the scientific publications and the patent documents pertinent to the topic drilling fluids with xanthan gum, it was viable to draw several indicators related to the topic under study. These indicators have helped analyze the technological scenario of xanthan gum in the period of 40 years.

\subsection{World Panorama and Perspectives of Xanthan Gum by Means of Scientific Publications}

For the collection of the scientific data, the database of Web of Science was used. The search was delimited considering the period from 1974 to 2014. As search strategy the following key words in the "TOPIC" field were used: together with the Boolean operator "OR" (xanthan gum* OR "gum xanthan*” OR "polysaccharide* xanthan"). This search resulted in 3464 scientific publications, of which $89.9 \%$ (3114) are available in the form of articles, $8.3 \%$ (286) as procedures, $2.4 \%$ (85) as reviews, $2.4 \%$ (82) as meeting abstract and less that $1.0 \%$ others.

Figure 1 shows the evolution of the number of scientific publications on the topic "xanthan gum", in the period between 1974 and 2014. A rising curve of the scientific production is observed, when the number of scientific publications indexed in the consulted database rose at an average rate of $12 \%$ per year.

Figure 2 shows the results of the analysis of 3,464 scientific publications classified by the authors' country of origin. It is observed that the US lead the ranking with 573 (16.5\%) publications, followed by India with 269 (7.8\%), England with 263 (7.6\%), Japan with 234 (6.8\%) and China with 227 (6.6\%) publications. Canada and Brazil are alike, with $5.4 \%$ of publications (187 and 186 records, respectively). This search indicated a total of 64 countries. It is also observed that Brazil occupies the 7th position in the world ranking of scientific output in the theme "xanthan", with 186 publications indexed in the database.

Table 1 presents the 3,464 scientific publications, sorted by area of expertise in the period of 40 years.

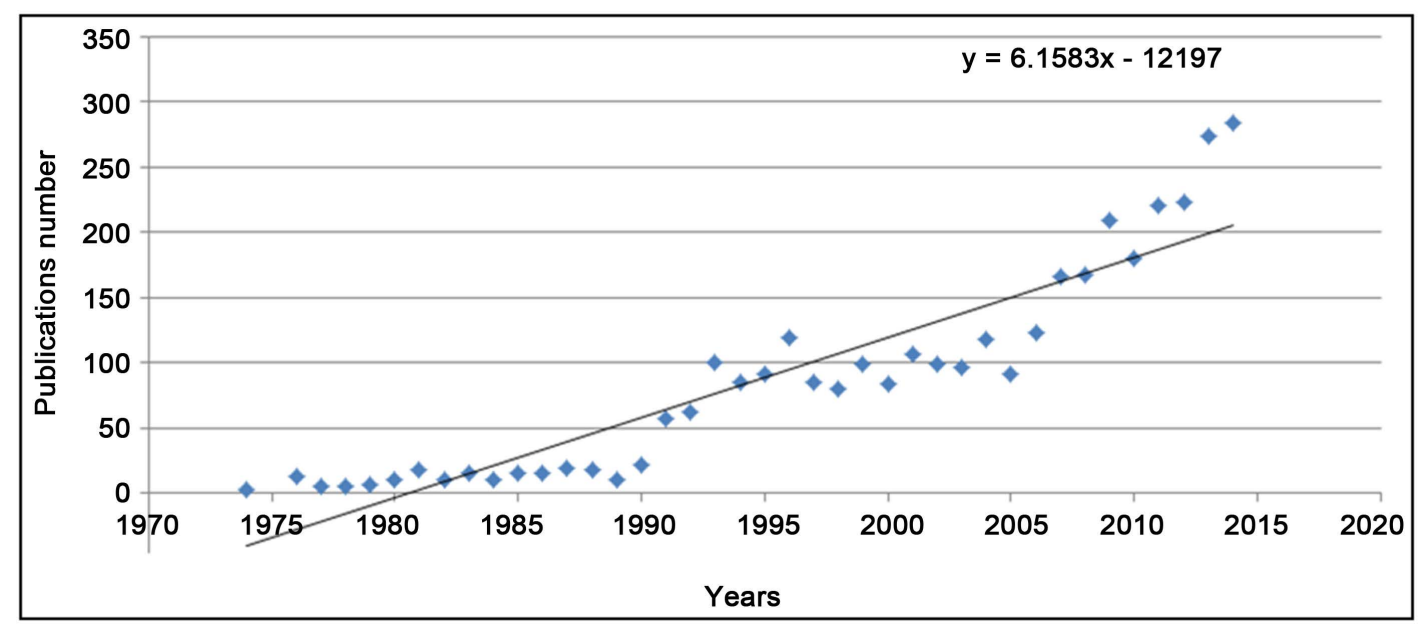

Figure 1. Number of scientific publications xanthan: 1974-2014 [11].

Table 1. Scientific publications about: xanthan, classified by field of study: 1974-2014 [11].

\begin{tabular}{ccc}
\hline Research Areas & Record Count & \% of 3464 Publications \\
\hline Food Science Technology & 1091 & 31.495 \\
Chemistry & 1046 & 30.196 \\
Polymer Science & 512 & 14.781 \\
Engineering & 511 & 14.752 \\
Biotechnology Applied Microbiology & 391 & 11.288 \\
Pharmacology Pharmacy & 295 & 8.516 \\
Biochemistry Molecular Biology & 261 & 7.535 \\
Materials Science & 160 & 4.619 \\
Agriculture & 147 & 4.244 \\
Microbiology & 132 & 3.811 \\
\hline
\end{tabular}




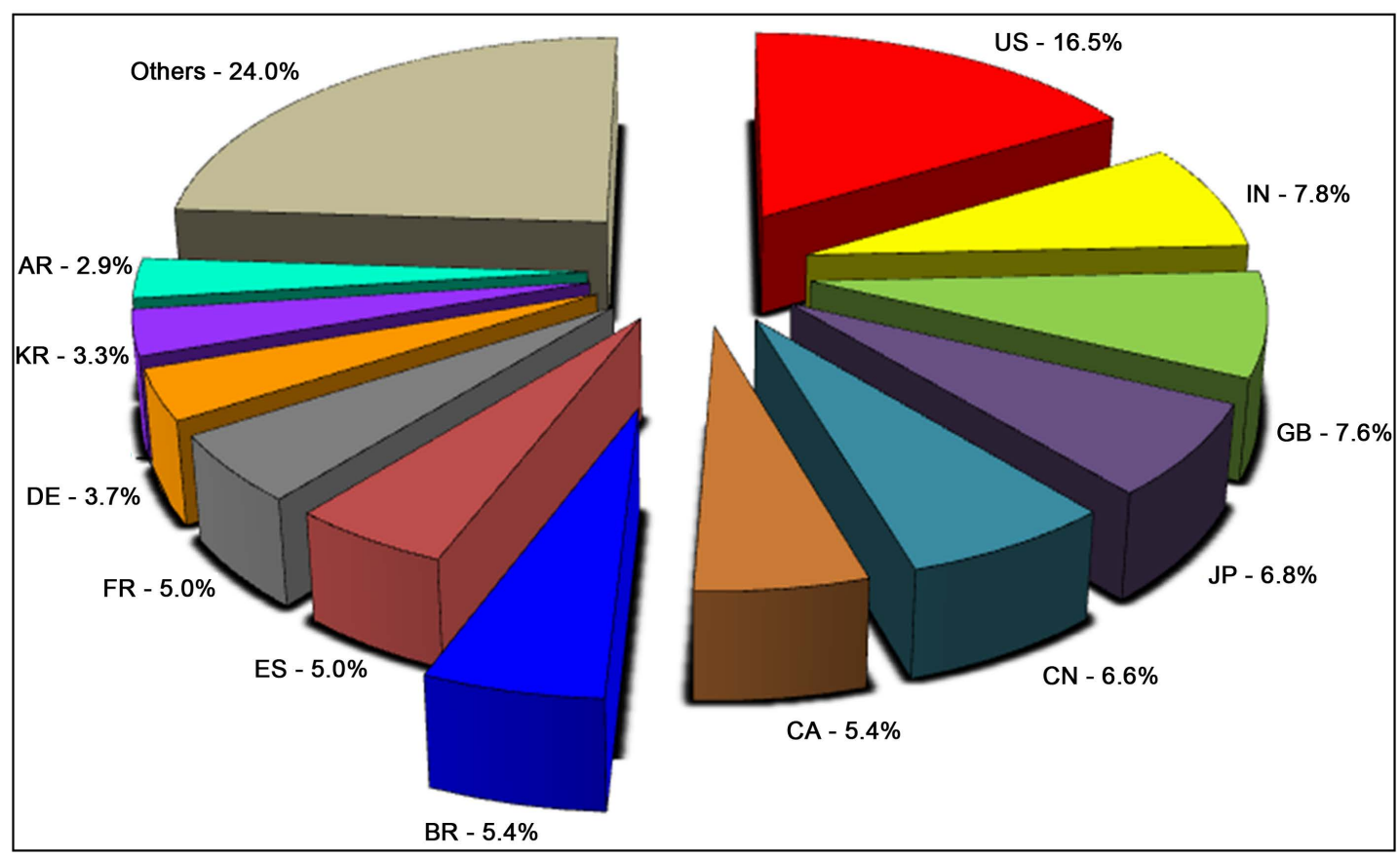

Figure 2. Scientific publications of xanthan by country: 1974-2014 [11].

It is noted that a significant percentage of publications is directly associated with a specific area: Food Science Technology (31.495\%), Chemistry (30.196\%), followed by Polymer Science (14.781\%) and Engineering (14.752\%). The remaining areas are located at much lower levels in the range of $11.288 \%$ to $3.811 \%$ of publications classified in their respective areas. According to the information in the consulted basis, 71 areas of knowledge were identified, confirming the concentration of the themes in a few areas. It is worth noting that a given publication may be classified in more than one area of expertise.

Table 2 shows the analysis of the number of scientific publications in relation to the origin of the authors' institutions.

Considering the institutions, the Centre National de La Recherche Scientifique CNRS, in France, leads the world ranking, with 68 publications in the observed period, followed by Consejo Nacionale de Investigaciones Científicas Y Tecnicas CONICET, in Argentina, with 67 and the Consejo Superior de Investigaciones Cientificas CSIC, in Spain, with 58 publications. The Universidad Nacional Autonoma de Mexico and Aristotle University of Thessaloniki, in Greece with 43 and 39 publications, respectively and the Council of Scientific Industrial Research CSIR, India, with 38 publications in the same period are also noteworthy. Among the top 10 organizations in the ranking of scientific output, 4 institutions belong to North America.

Figure 3 shows the results of the analysis of 65 scientific publications with theme drilling fluid with additive xanthan gum classified by the authors' country of origin. It is observed that the Brazil and the U.S.A lead the ranking with 15 (23.1\%) publications each country, followed by India with 6 (9.2\%), Algeria (DZ), Canada (CA), Iran (IR) and China (CN) with 4 (6.1\%) publications each country. France (FR), Italy (IT), Malaysia (MY), Norway (NO) and Turkey (TR) alike, with 3.1\% of publications. This search indicated a total of 18 countries, in which the five countries with the lowest number of publications represent $4.7 \%$.

Table 3 presents 65 scientific publications sorted by area of expertise in the period of 40 years.

It is noted that a significant percentage of publications is directly associated with a specific area: Engineering (64.615\%), Energy Fuels (32.308\%), followed by Polymer Science (13.846\%) and Chemistry (12.308\%). The remaining areas are located at much lower levels in the range of $9.231 \%$ to $1.538 \%$ of publications classified in their respective areas. According to the information in the consulted basis, 11 areas of knowledge were identified, confirming the concentration of the themes in a few areas. It is worth noting that a given publication may be classified in more than one area of expertise.

Table 4 shows the analysis of the number of scientific publications in relation to the origin of the authors' institutions. 


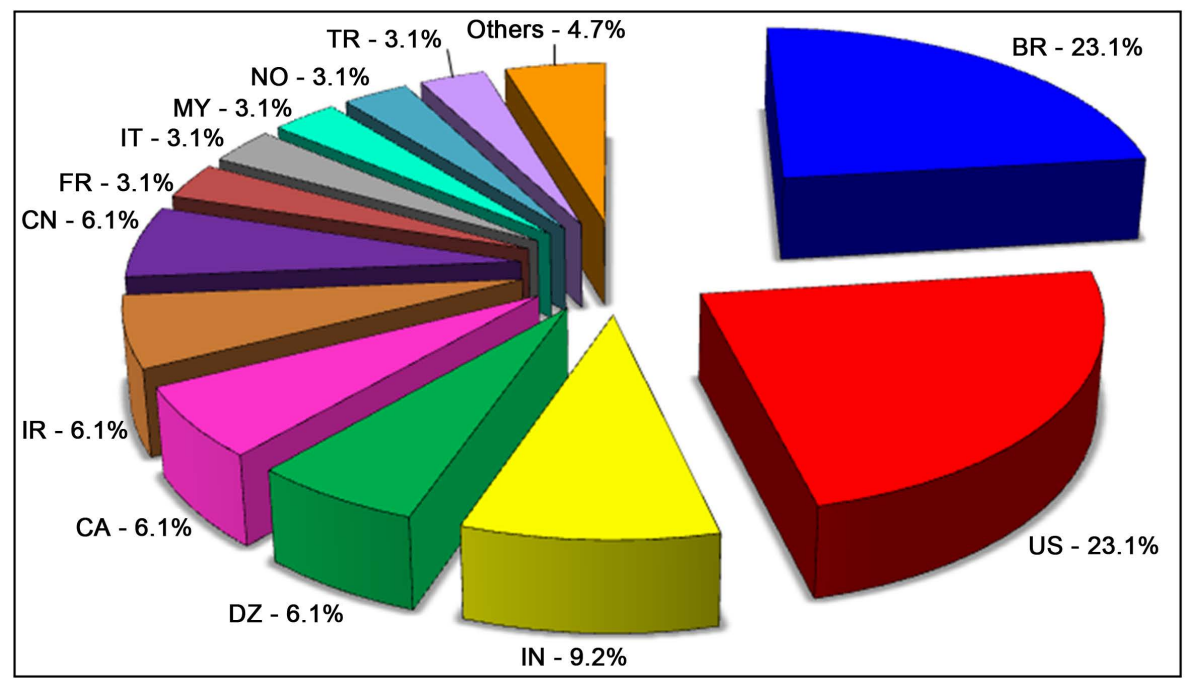

Figure 3. Scientific publications of drilling fluid with xanthan by country: 1974-2014 [11].

Table 2. Scientific publications about: xanthan, classified by the home institution of the authors: 1974-2014 [11].

\begin{tabular}{ccc}
\hline Organizations-Enhanced & Record Count & \% of 3464 Publications \\
\hline Centre National de La Recherche Scientifique CNRS, France & 68 & 1.963 \\
Consejo Nac. de Investig. Cient. Y Tec. CONICET, Argentina & 67 & 1.934 \\
Consejo Superior de Investigaciones Cientificas CSIC, Spain & 58 & 1.674 \\
Universidad Nacional Autonoma de Mexico & 43 & 1.241 \\
Aristotle University of Thessaloniki, Greece & 39 & 1.126 \\
Council of Scientific Industrial Research CSIR, India & 38 & 1.097 \\
University of California System & 37 & 1.068 \\
University of Nottingham & 36 & 1.039 \\
Agriculture Agri Food Canada & 35 & 1.010 \\
United States Department of Agriculture USDA & 35 & 1.010 \\
\hline
\end{tabular}

Table 3. Scientific publications about: drilling fluid with xanthan, classified by field of study: 1974-2014 [11].

\begin{tabular}{ccc}
\hline Research Areas & Record Count & \% of 65 Publications \\
Engineering & 42 & 64.615 \\
Energy Fuels & 21 & 32.308 \\
Polymer Science & 9 & 13.846 \\
Chemistry & 8 & 12.308 \\
Environmental Sciences Ecology & 6 & 9.231 \\
Materials Science & 5 & 7.692 \\
Geology & 3 & 4.615 \\
Mechanics & 2 & 3.077 \\
Biotechnology Applied Microbiology & 1 & 1.538 \\
Metallurgy Metallurgical Engineering & 1 & 1.538 \\
Science Technology Other Topics & 1 & 1.538 \\
\hline
\end{tabular}

Table 4. Scientific publications about: drilling fluid with xanthan, classified by the home institution of the authors: 19742014 [11].

\begin{tabular}{ccc}
\hline Organizations-Enhanced & Record Count & \% of 65 Publications \\
\hline Petrobras SA & 6 & 9.231 \\
Universidade Federal do Rio de Janeiro & 6 & 9.231 \\
Petroleum University Technology & 4 & 6.154 \\
University of Alberta & 4 & 6.154 \\
University of Oklahoma & 4 & 6.154 \\
University of Tulsa & 4 & 6.154 \\
India School of Mines & 3 & 4.615 \\
Universidade de São Paulo & 3 & 4.615 \\
Universidade Federal de Uberlândia & 3 & 4.615 \\
Universiti Malaya & 2 & 3.077 \\
\hline
\end{tabular}


Considering 72 institutions, Petrobras SA and Universidade Federal do Rio de Janeiro, in Brazil, lead the world ranking, with 6 publications each one, in the observed period, followed by Petroleum University Technology, in Iran, University of Alberta, in Canada, University of Oklahoma and University of Tulsa, in USA, with 4 publications each. The India School of Mines, Universidade de São Paulo and Universidade Federal de Uberlândia, both in Brazil, (3 publications, each) and the Universiti Malaya, in Malaysia, with 2 publications in the same period are also noteworthy. Among the top 10 organizations in the ranking of scientific output, 4 institutions are in Brazil and 2 are in USA.

\subsection{World Panorama and Perspectives of Xanthan Gum by Means of Technological Monitoring of Patents}

For the choice of the database, INPI, Espacenet, USPTO, Patent Scope and Derwent II were evaluated. In order to grant a greater scope to the patent study, general terms were selected related to the topic, such as "drilling fluid *xanthan" OR "fluid drilling* xanthan” OR "xanthan* drilling fluid” OR "xanthan* fluid drilling”. In this study, the whole period of available information in each database was taken into account.

Table 5 presents the results of the searches in the different searched databases, as well as their respective search strategies.

Table 6 presents the results of the search strategy specific in the different searched databases, as well as their respective search strategies.

The choice of the database took into account the availability of access, scope and quality of information.

The availability of access to the databases: Patent Scope, USPTO, Espacenet and INPI are free of charge, while DERWENT II is a private database which encompasses patent documents published worldwide. However, in Brazil, given its relevance, it is available on the portal of CAPES, for free consultation by Universities, Federal Institutes (IF) and Institutes of P \& D.

As the results presented in Table 5 are analyzed, it is observed that the database DERWENT II presents a more comprehensive scope when compared with other free databases. The search using the DERWENT II data-

Table 5. Terms used in the search strategy generic and applied in patent database [12]-[16].

\begin{tabular}{ccc}
\hline Database & Keywords & Record Count \\
\hline PATENT SCOPE & EN_TI:(“xanthan gum*” or “gum xanthan*”) & 4,705 \\
OR EN_AB:(“xanthan gum*” or "gum xanthan*”) & 516 \\
ESPACENET & (TTL/(xanthan AND gum) OR ABST/(xanthan AND gum)) & 6,760 \\
DERWENT & "xanthan gum*” or "gum xanthan*” in the title or abstract & 18,544 \\
INPI ${ }^{1}$ & Topic $=$ (xanthan gum*) OR Topic = ("gum xanthan*”) Databases = CDerwent, & 23 \\
\hline
\end{tabular}

Table 6. Terms used in the search strategy specific and applied in patent database [12]-[16].

\begin{tabular}{|c|c|c|}
\hline Database & Keywords & Record Count \\
\hline PATENT SCOPE & $\begin{array}{l}\text { EN_TI:(“xanthan gum* drilling fluid” or "gum xanthan* drilling fluid”) OR } \\
\text { EN_AB:(“xanthan gum* drilling fluid” or "gum xanthan* drilling fluid”) }\end{array}$ & 69 \\
\hline USPTO & $\begin{array}{l}\text { (TTL/(xanthan AND gum) AND drilling) AND fluid) } \\
\text { OR ABST/(((xanthan AND gum) AND drilling) AND fluid)) }\end{array}$ & 9 \\
\hline ESPACENET & "xanthan gum drilling fluid*” or "gum xanthan drilling fluid*” in the title or abstract & 69 \\
\hline DERWENT & $\begin{array}{c}\text { Topic = (“drilling fluid* xanthan”) OR Topic = ("fluid drilling* xanthan”) } \\
\text { OR Topic = ("xanthan* drilling fluid”) OR Topic = ("xanthan* fluid drilling”) } \\
\text { Databases = CDerwent, EDerwent, MDerwent Timespan = All years }\end{array}$ & 366 \\
\hline INPI & Title: xantana and fluido and perfuração* Abstract: xantana and fluido and perfuração* & 1 \\
\hline
\end{tabular}

\footnotetext{
${ }^{1}$ The base includes only applications in Brazil.
} 
base recovered 18,544 patent filings, followed by the databases Espacenet, Patent Scope, USPTO, and INPI with 6760; 4705; 516 and 23 patent registrations respectively.

Regarding the quality of information, DERWENT II database comprises a patent database with over 30 million patent documents filed in several countries. In addition, the titles and the abstracts of patent applications of this database are rewritten by specialists of the technological areas covered by the inventions in order to facilitate the retrieval of patent applications by means of key words used in the search strategies.

In face of the results of the databases analyzed, the DERWENT II database was chosen for the technological monitoring of xanthan gum.

As the results presented in Table 6 are analyzed, it is observed that the database DERWENT II presents a more comprehensive scope when compared with other free databases. The search using the DERWENT II database recovered 366 patent filings, followed by the databases Espacenet, Patent Scope, USPTO, and INPI with 69; 69; 9 and 1 patent registration respectively.

In face of the results of the databases analyzed, the DERWENT II database was chosen for the technological monitoring of xanthan applied with additive drilling fluid.

Figure 4 shows the evolution of the number of patents registered in the world on the theme "xanthan applied with additive drilling fluid", in the period from 1974 to 2014. An upward curve of the patent production is observed. In the period between 1974 and 1998, a modest growth is noted. From 1999 onwards a significant increase is observed and, in 2013, a record is achieved with 37 patent applications of xanthan gum as an additive drilling fluid, which represents the mounting interest on patenting applications of xanthan in drilling fluid.

Figure 5 shows the results of the analysis of 366 patent records classified by the depositor countries, during the studied period. It is observed that the USA leads the ranking with 51 (51\%) patent filings, followed by China with 19 (19\%) records. Of the total patent filings sorted by others country, which are only 6\% (6), two patents were deposited in Brazil.

The results of the patent survey have enabled the identification of the following: (i) the main areas of specialization associated with the set of patents, according to indexation of the areas by databases consulted, (ii) the number of depositors and highlights, emphasizing the presence of companies, (iii) the main inventors, and (iv) an analysis by the International Patent Classification code (IPC), which reveals the ICP subclasses and their respective codes of greater representativeness for further monitoring of the evolution of intellectual property on the theme in the coming years.

Table 7 presents the set of patents collected according to the classification with the ten main areas of specialization of the indexing system itself in the mentioned database. The survey indicated a total of 19 areas of expertise.

When analyzing the patent information shown in Table 7, there is a significant percentage referring to the area of chemistry (98.087\%) and in a second level, three other areas: engineering (93.989\%), energy fuels (92.623\%) and polymer science (89.891\%) respectively. In this ranking with the ten major areas, other areas show $34.699 \%$ to $7.104 \%$ from the total of patents classified according to the very system of Derwent Innovations Index database. It is worth noting, however, that a given patent may be classified in more than one area of expertise.

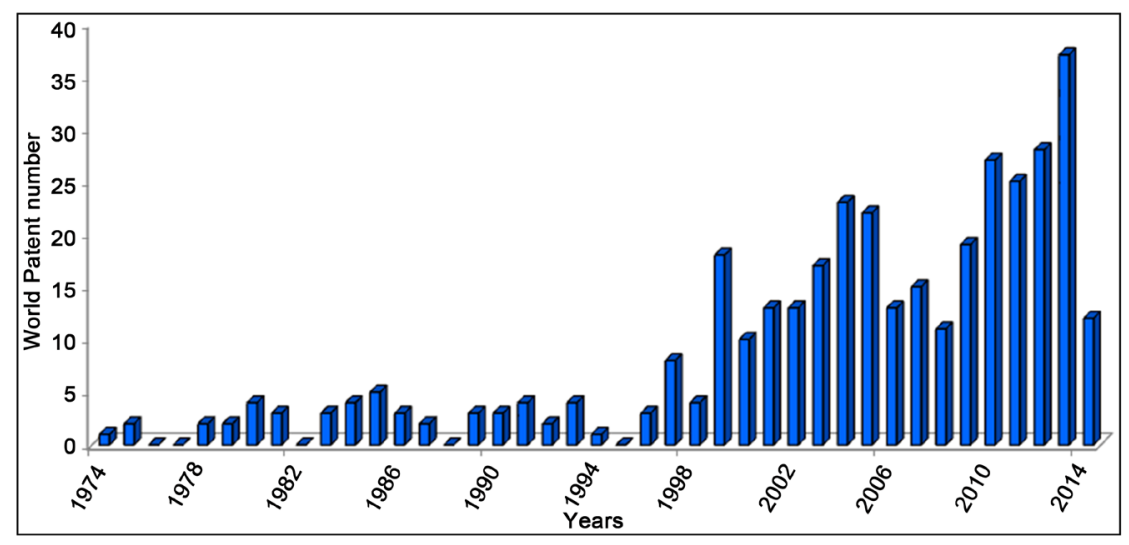

Figure 4. Number patents of drilling fluid with xanthan in the world: 1974-2014 [15]. 


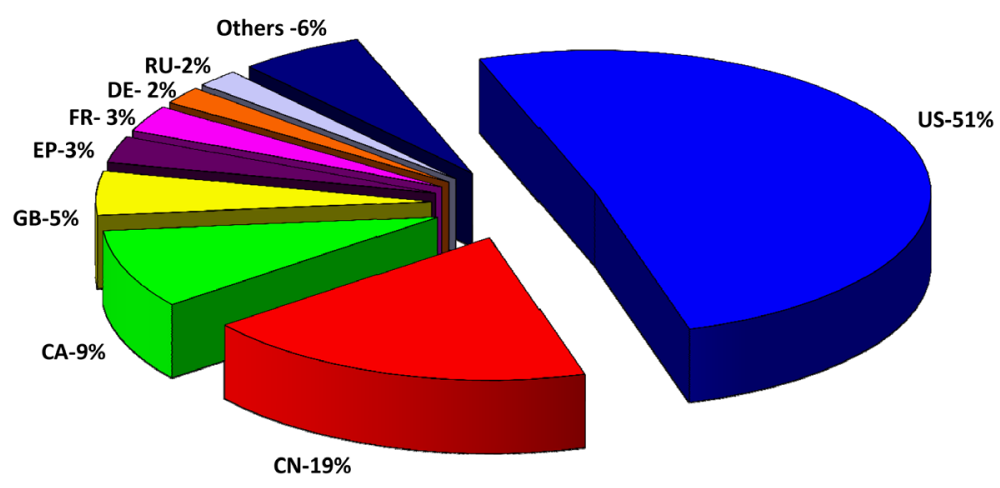

Figure 5. Records of patents, in \%, of drilling fluid with xanthan by country: 1974-2014 [15].

Table 7. World patent: drilling fluid with xanthan, classified by area of expertise: 1974-2014 [15].

\begin{tabular}{ccc}
\hline Subject Areas & Record Count & \% of 366 Patents \\
\hline Chemistry & 359 & 98.087 \\
Engineering & 344 & 93.989 \\
Energy Fuels & 339 & 92.623 \\
Polymer Science & 329 & 89.891 \\
Mineral Processing & 127 & 34.699 \\
Biotechnology Applied Microbiology & 41 & 11.202 \\
Food Science Technology & 34 & 9.290 \\
Photographic Technology & 32 & 8.743 \\
Pharmacology and Pharmacy & 27 & 7.377 \\
Materials Science & 26 & 7.104 \\
\hline
\end{tabular}

The same set of patents was analyzed in relation to their depositors and their respective codes of Derwent depositor. Table 8 shows that the leading company is Halliburton (55 patents), followed by Schlumberger (39 patents), Texas United (12 patents) and M-I LLC (11 patents). The remaining depositors which stand out in the ranking area are: Baker Hughes Inc, China Petroleum Corp and Hercules Inc with 10 patent applications each. The search has also indicated a total of 496 depositors. A more attentive examination reveals that the last four table depositors have similar names, indicating that they may be part of the same company.

The same set of patents was analyzed in relation to the depositor code. Table 9 shows that the leading company is Halliburton (HALL-C) with 57 patents, followed by China Petroleum \& Chemical Corp (CNPC-C) with 18 patents and Sinopec Shengli Petroleum Co Ltd. (SNPC-C) with 15 patents. The remaining depositors to stand out in the ranking are: M-I Drilling Fluids UK Ltd. (MIWO-C), Schlumberger (SLMB-C), Texas United Chemical Co LLC (TEXA-N), University China of Petroleum (UYCH-N) with 13, 13, 12 and 11 patent applications respectively. The search has also indicated a total of 384 different codes of depositors.

In Table 10 the main inventors of drilling fluid with xanthan related to the subject of drilling fluid with xanthan were identified. The leading inventor is Dobson J. W. (12 patents), followed by Reddy B. R. (11 patents) and Todd B. L. (10 patents). The other inventors who excel in the ranking are: Munoz T., Saini R., Zhang J. with 8 patent applications each. The search had also indicated a total of 1,137 inventors.

In order to assess the technological trajectories, an analysis of the top ten ranking along two different periods of time was carried out, which allowed a more detailed analysis of the world panorama.

Table 11 shows the results of the analysis of 366 patents according to the subclasses and respective codes of the International Patent Classification (IPC). In this research, 760 different classifications on the subject under study were recovered considering the period between 1974 and 2014.

When analyzing the information in Table 11, there is a significant percentage concerning the classification C09K-008/02, Well-drilling compositions, with 26.503\%, followed by C09K-007/02, Aqueous fluids containing organic or inorganic compounds, with $23.770 \%$ and C09K-008/12, Containing synthetic organic macromolecular compounds or their precursors, with $15.027 \%$. In this ranking with ten main classifications, the other ratings range from $13.934 \%$ to $8.197 \%$ from the total of classified patents.

Table 12 shows the results of the analysis of the 253 patents taking into account no more than the last decade, i.e., along the period between 2004 and 2014. In this search, 381 different classifications were recovered. 
Table 8. World patent: drilling fluid with xanthan, classified by depositor: 1974-2014 [15].

\begin{tabular}{ccc}
\hline Assignee Name & Record Count & \% of 366 Patents \\
\hline Halliburton Energy Services Inc & 55 & 15.027 \\
Texas United Chemical Co LLC & 12 & 3.279 \\
M-I LLC & 11 & 3.005 \\
Baker Hughes Inc. & 10 & 2.732 \\
China Petroleum \& Chemical Corp & 10 & 2.732 \\
Hercules Inc. & 10 & 2.732 \\
Schlumberger Holdings Ltd. & 10 & 2.732 \\
Schlumberger Technology BV & 10 & 2.732 \\
Services Petroliers Schlumberger & 10 & 2.732 \\
Schlumberger Canada Ltd. & 9 & 2.459 \\
\hline
\end{tabular}

Table 9. World patent: drilling fluid with xanthan, classified by the depositor code: 1974-2014 [15].

\begin{tabular}{ccc}
\hline Assignee Code & Record Count & \% of 366 Patents \\
\hline HALL-C & 57 & 15.574 \\
CNPC-C & 18 & 4.918 \\
SNPC-C & 15 & 4.098 \\
MIWO-C & 13 & 3.552 \\
SLMB-C & 13 & 3.552 \\
TEXA-N & 12 & 3.279 \\
UYCH-N & 11 & 3.005 \\
BAKO-C & 10 & 2.732 \\
HERC-C & 10 & 2.732 \\
RHOD-C & 9 & 2.459 \\
\hline
\end{tabular}

Table 10. World patent of drilling fluid with xanthan, classified by inventor: 1974-2014 [15].

\begin{tabular}{ccc}
\hline Inventor & Record Count & \% of 366 Patents \\
DOBSON J W & 12 & 3.279 \\
REDDY B R & 11 & 3.005 \\
TODD B L & 10 & 2.732 \\
MUNOZ T & 8 & 2.186 \\
SAINI R K & 8 & 2.186 \\
ZHANG J & 8 & 2.186 \\
MELBOUCI M & 7 & 1.913 \\
WANG C & 7 & 1.913 \\
ZHAO S & 7 & 1.913 \\
\hline
\end{tabular}

Table 11. World patent of drilling fluid with xanthan, classified by IPC: 1974-2014 [13] [15].

\begin{tabular}{|c|c|c|c|}
\hline IPC & Description & $\begin{array}{l}\text { Record } \\
\text { Count }\end{array}$ & $\begin{array}{l}\% \text { of } 366 \\
\text { Patents }\end{array}$ \\
\hline C09K-008/02 & ·Well-drilling compositions & 97 & 26.503 \\
\hline C09K-007/02 & -Aqueous fluids containing organic or inorganic compounds & 87 & 23.770 \\
\hline C09K-008/12 & $\cdots$ containing synthetic organic macromolecular compounds or their precursors & 55 & 15.027 \\
\hline C09K-008/08 & …containing natural organic compounds, e.g. polysaccharides, or derivatives there of & 51 & 13.934 \\
\hline C09K-008/035 & ‥ Organic additives & 43 & 11.749 \\
\hline C09K-008/60 & Compositions for stimulating production by acting on the underground formation & 39 & 10.656 \\
\hline E21B-043/00 & $\begin{array}{l}\text { Methods or apparatus for obtaining oil, gas, water, soluble or melt able materials } \\
\text { so a slurry of minerals from wells (applicable only to water E03B; obtaining oil-bearing } \\
\text { deposits or soluble or melt able materials by mining techniques E21C 41/00 }\end{array}$ & 39 & 10.656 \\
\hline E21B-021/00 & $\begin{array}{l}\text { Methods or apparatus for flushing boreholes, e.g. by use of exhaust air from motor } \\
\text { (freeing objects stuck in boreholes by flushing E21B31/03; well drilling compositions C09K8/02) }\end{array}$ & 35 & 9.563 \\
\hline C09K-007/00 & Compositions are classified according to their major constituent & 33 & 9.016 \\
\hline E21B-043/25 & $\begin{array}{l}\text { Methods for stimulating production (dump bailers E21B 27/02; vibration generating } \\
\text { arrangements E21B 28/00; chemical compositions therefor C09K 8/60) }\end{array}$ & 30 & 8.197 \\
\hline
\end{tabular}


Table 12. World patent of drilling fluid with xanthan, classified by IPC: 2004-2014 [13] [15].

\begin{tabular}{|c|c|c|c|}
\hline IPC & Description & $\begin{array}{l}\text { Record } \\
\text { Count }\end{array}$ & $\begin{array}{c}\% \text { of } 253 \\
\text { Patents }\end{array}$ \\
\hline C09K-008/02 & Well-drilling compositions & 81 & 32.016 \\
\hline C09K-008/12 & $\cdots$ containing synthetic organic macromolecular compounds or their precursors & 54 & 21.344 \\
\hline C09K-008/035 & $\cdots$ Organic additives & 42 & 16.601 \\
\hline C09K-008/08 & …containing natural organic compounds, e.g. polysaccharides, or derivatives thereof & 41 & 16.206 \\
\hline C09K-008/60 & Compositions for stimulating production by acting on the underground formation & 31 & 12.253 \\
\hline E21B-043/00 & $\begin{array}{l}\text { Methods or apparatus for obtaining oil, gas, water, soluble or melt able materials } \\
\text { so a slurry of minerals from wells (applicable only to water E03B; obtaining } \\
\text { oil-bearing deposits or soluble or melt able materials by mining techniques E21C } 41 / 00\end{array}$ & 30 & 11.858 \\
\hline C09K-007/02 & Aqueous fluids containing organic or inorganic compounds & 29 & 11.462 \\
\hline C09K-008/10 & $\cdots \cdot$ Cellulose or derivatives thereof & 28 & 11.067 \\
\hline E21B-021/00 & $\begin{array}{l}\text { Methods or apparatus for flushing boreholes, e.g by use of exhaust air from motor } \\
\text { (freeing objects stuck in boreholes by flushing E21B31/03; } \\
\text { well drilling compositions C09K8/02) }\end{array}$ & 28 & 11.067 \\
\hline C09K-008/24 & ......Polymers & 26 & 10.277 \\
\hline
\end{tabular}

In Table 12, concerning the period of 2004-2014, a significant percentage of the classification C09K-008/02 is noted. Well-drilling compositions, with $32.016 \%$, followed by the C09K-008/12, Containing synthetic organic macromolecular compounds or their precursors, with $21.344 \%$ and C09K-008/035, Organic additives, with $16.601 \%$. In this ranking with ten main classifications, the other ratings have from $16.206 \%$ to $10.277 \%$ of the total of classified patents. It is worth noting, however, that a given patent may be classified in more than one IPC classification.

\section{Conclusions}

From the survey of the published scientific papers and the patents deposited between the years of 1974 and 2014, some conclusions may be drawn:

- The methodology applied for the analysis of the patent data and the choice of the DERWENT II database for the technological monitoring have proved to be adequate due to the straightforwardness offered by the free access in the centers of $\mathrm{R} \& \mathrm{D}$ in Brazil, a larger scope of the patent data published in the world and the high reliability of the information available in the mentioned database;

- Analyzing the scientific publications and the patent applications per year, it may be observed that there was a linear increase in the number of scientific papers and a nonlinear increase in the number of patent applications on the subject. The year 2013 presented the highest number of patent applications;

- Concerning the countries mentioned, it is observed that the United States and China stand out both in relation to the publication of papers as well as in the amount of patent filing. In scientific publications with theme drilling fluid with additive xanthan gum classified by the authors' country of origin, it is observed that Brazil and the US lead the ranking with 15 (23.1\%). Considering 72 institutions, Petrobras SA and Universidade Federal do Rio de Janeiro, in Brazil, lead the world ranking, with 6 publications each;

- In relation to the areas of knowledge, it was observed that engineering stands out in the publication of papers and the areas of chemistry, engineering, energy fuels and polymer science are noticeable in numbers of patent applications.

Applications of xanthan gum with additive drilling fluid are rather broad and are in constant development, mainly in the chemical, engineering and energy fuels areas. From the analysis of patent filings in the periods of 1974-2014 and 2004-2014, a significant percentage associated with the classification C09K may be observed, in both periods. This result establishes the use of xanthan gum as an additive drilling fluid. In the period from 2004 to 2014, an increase of C09K classification was equally observed, which is associated with the use of xanthan in well-drilling compositions. 


\section{References}

[1] Baltar, C.A.M. and Luz, A.B. (2013) Insumos Minerais para a Perfuração de Poços de Petróleo. CETEM/UFPE, Recife, 13.

[2] Khodja, M., Canselier, J.P., Bergaya, F., Fourar, K., Khodja, M., Cohaut, N. and Benmounah, A. (2010) Shale Problems and Water-Based Drilling Fluid Optimization in the Hassi Messaoud Algerian Oil Field. Applied Clay Science, 49, 383-393.

[3] Nascimento, R.C.A.M., Amorim, L.V. and Sanatana, L.N.L. (2010) Desenvolvimento de fluidos aquosos com bentonita para perfuração de poços de petróleo onshore. Cerâmica, 56, 179-187.

[4] Grand View Research (2014) Global Drilling Fluids Market Analysis by Product (OBF, SBF, WBF) by Application (Offshore, Onshore) Expected to Reach USD 14.92 Billion by 2020: Grand View Research, Inc. http://www.grandviewresearch.com/press-release/global-drilling-fluids-market

[5] Borges, C.D. and Vendruscolo, C.T. (2008) Goma Xantana: Características e condições operacionais de produção. Ciências Biológicas e da Saúde, 29, 171-188.

[6] Born, K., Langendorff, V., Boulenguer, P., Vandamme, E.J., De Baets, S. and Steinbüchel, A. (2002) Xanthan. In: Biopolymers-Biology, Chemistry, Biotechnology and Applications, Weley-VCH, Weinheim, 259-291.

[7] Machado, B.A.S., Reis, J.H.O., Figueiredo, T.V.B. and Druzian, J.I. (2012) Mapeamento Tecnólogico da Goma Xantana sob o Enfoque em Pedidos de Patentes Depositados no Mundo entre 1970 a 2009. São Cristóvão/SE, 2, 154165.

[8] Melo, K.C., Dantas, T.N.C. and Barros Neto, E.L. (2013) Influência da Temperatura na Reologia de Fluídos de Perfuração Preparados com Carboximetilcelulose, Goma Xantana e Bentonita. Holos, 5, 3-18.

[9] Canongia, C.L., Santos, D.M., Santos, M.M. and Zackiewicz, M. (2004) Foresight, Inteligência Competitiva e Gestão do Conhecimento: instrumentos para a gestão da inovação. Revista Gestão \& Produção, 11, 231-238.

[10] Carvalho, D.S., Oliveira, L.G., Winter, E. and Mothé, C.G. (2009) Technological Foresight Based on Citing and Cited Patents of Cellulose with Pharmaceutical Applications. Journal of Technology Management \& Innovation, 4, 32-41.

[11] Thomson Reuters. Web of Science Database (2015). http://apps-webofknowledge.ez24.periodicos.capes.gov.br/WOS_GeneralSearch_input.do?product=WOS\&search_mo de=GeneralSearch\&SID=3FNIszaDnfRT7Jc3AAb\&preferencesSaved

[12] Espacenet Website (2015). http://ep.espacenet.com/advancedSearch?locale=en_EP

[13] INPI Website (2015). https://gru.inpi.gov.br/pPI/jsp/patentes/PatenteSearchAvancado.jsp

[14] Patent Scope Website (2015). http://www.wipo.int/pctdb/en/search-adv.jsp

[15] Thomson Reuters. Derwent Innovations Index Database (2015). http://apps-webofknowledge.ez24.periodicos.capes.gov.br/DIIDW_GeneralSearch_input.do?product=DIIDW\&search_ mode $=$ GeneralSearch \&SID=3FNIszaDnfRT7Jc3AAb\&preferencesSaved

[16] USPTO Website (2015). http://www.uspto.gov/ 